


\section{Article Artículo Paper Formació antiracista per als professionals de l'acció social}

\section{Carles Serra ${ }^{1}$}

\section{Mostafá Shaimi ${ }^{1}$}

\section{Resum}

En aquest article es proposa una reflexió entorn a la necessitat d'apostar decididament per l'enfocament antiracista com eix central de les polítiques relacionades amb la immigració, la integració, la ciutadania i la manera com en la nostra societat ens volem relacionar amb les persones i collectius que són definits com a "diferents". L'article defensa que l'antiracisme, que hauria de ser l'eix central d'aquestes polítiques, ha quedat desdibuixat darrera de l'aposta institucional per la "interculturalitat" $i$ això ha fet que les polítiques i les accions de caràcter antiracista hagin estat molt poc desenvolupades als nostre país. Per altra part, l'article planteja quines són les qüestions clau que s'haurien d'abordar en una proposta de formació antiracista adreçada als professionals que treballen en l'àmbit social. Segons els autors algunes de les claus de la formació haurien de passar per: el desenvolupament de la seva capacitat per a reconèixer les diferents formes de racisme; entendre com el racisme interactua amb altres eixos de desigualtat; aconseguir que els profes- 
sionals coneguin i dominin recursos i estratègies per a fer-hi front; que assumeixin l'antiracisme com a compromís inherent al seu exercici professional, i que prioritzin l'atenció a les víctimes i l'apoderament de les persones racialitzades i de la resta d'agents socials que treballen per a fer front a les diferents formes de discriminació racista.

Paraules clau: racisme, antiracisme, professionals, formació

\begin{abstract}
This article proposes a reflection on the need to make a firm commitment to the anti-racist approach as the central axis of policies related to immigration, integration, citizenship and the way in our society we want to relate with people and groups who are defined as "different". The article argues that anti-racism, which should be the central axis of these policies, has been left behind the institutional commitment to "interculturality" and this has led to policies and actions of an anti-racist nature have been very underdeveloped in our country. On the other hand, the article raises the key issues that should be addressed in a proposal for anti-racist training aimed at professionals working in the social field. According to the authors, some of the keys to training should go through: the development of their ability to recognize the different forms of racism; understand how racism interacts with other axes of inequality; getting professionals to know and master resources and strategies to deal with them; that they assume anti-racism as a commitment inherent in their professional practice, and that they prioritize the care of victims and the empowerment of racialized people and other social agents who work to deal with the different forms of racist discrimination.
\end{abstract}

Keywords: racism, anti-racism, professionals, training. 
L'abordatge del racisme és un dels grans buits en les polítiques i la formació dels professionals de l'àmbit social. Mai no ha estat una prioritat, ni ha rebut l'atenció que requereixen les pràctiques de vulneració dels drets més bàsics de les persones. Lluny d'això, l'antiracisme ha quedat ocult rere el triangle que suposadament estructura la proposta política de la interculturalitat: 1 . Respecte de les "diferències" dins d'un marc de convivència compartit, 2. Defensa de la igualtat, i 3. Foment de la interacció, la convivència i la cohesió social (Generalitat de Catalunya 2017: 13-14).

L'antiracisme és part d'aquesta "defensa de la igualtat" (Generalitat de Catalunya 2017: 29-30). Però sembla difícil que pugui ser una prioritat, quan el racisme apareix implícitament com un vector de desigualtat més, al mateix nivell que el sexisme, les desigualtats socials i altres formes de desigualtat amb què més aviat hem après a conviure, més que no pas a lluitar-hi. I si la defensa de la igualtat passa per mantenir un context i unes regles del joc que ja es suposen igualitàries, difícilment podrem equiparar aquesta declaració de principis a l'antiracisme tal com es concep tant des de l'acadèmia, com des dels moviments socials. Com a molt, des d'aquesta declaració d'igualtat antiracista implícita en els plantejaments interculturals, ens podem proposar de lluitar contra les vulneracions de drets perpetrades per algunes persones que van més enllà del que es considera socialment acceptable. Però resulta que el racisme en la nostra societat no el podem considerar només com una tara pròpia de reductes extremistes i d'ignorants, i l'antiracisme ha demostrat que cal un treball molt més profund i transversal (Serra, 2002; Serra, Besalú i Casademont, 2016).

Catalunya és racista? Fer-nos aquesta pregunta podria ser un bon punt de partida a l'hora de plantejar per on hauria d'anar una política i una acció social clarament antiracista. I convindria que abans de respondre-la ens plantegéssim quina seria la nostra resposta si la pregunta fos si Catalunya és sexista o si vivim en una societat patriarcal. I és que emmirallar-nos en la lluita feminista resulta de gran ajuda a l'hora d'entendre el que és o el que hauria de ser la lluita antiracista. Després de dècades de lluita feminista, s'ha anat instal-lant en la societat la idea que les desigualtats de gènere estan presents en tots els àmbits i són un element estructurant de la nostra societat (diem que aquesta idea s'ha anat instal·lant en la nostra societat, si bé cal aclarir que ho ha anat fent de manera sempre precària, mai donant res per definitiu sinó ben al contrari, resistint els qui qüestionen encara la idea de la igualtat de gènere, consideren que s'ha anat massa enllà o fins i tot afirmen que ara s'han canviat les tornes i que ara són les dones les que s'han situat en una situació 
de privilegi que penalitza els homes en uns àmbits i processos socials concrets). Amb tot, s'ha anat estenent en la societat la convicció que el problema no és que hi hagi "alguns homes masclistes", sinó que el patriarcat (la ideologia i les relacions de poder que estableixen el domini dels homes sobre les dones) dona forma a l'organització social i cultural, és un sistema de dominació que ordena les relacions entre homes i dones, i dona a uns i altres un valor diferent i/o desigual (Pujal i Llombart, 2005).

Aquest també és el punt de partida de l'antiracisme: el racisme no és una excepció produïda per l'existència d'individus que, per extremisme, fanatisme o ignorància, vulneren el principi d'igualtat que regeix les relacions entre les persones de diferent origen o nacionalitat, aspecte físic o pràctica religiosa o cultural; el racisme és un sistema de dominació que històricament ha estat present en tots els àmbits de la societat, ha estructurat les relacions socials i ha impregnat la cultura (la manera com pensem la diversitat, el valor que assignem a determinats col-lectius i les seves produccions culturals, les expectatives i els judicis de valor que elaborem en relació a ells) (Parsons et al, 2004). I "històricament" no vol dir que tot això només sigui part del passat, sinó que forma part d'un bagatge amb què hem après a organitzar la societat, a relacionar-nos o a pensar-nos, i que si no treballem per a reconèixer-lo i a repensar-lo críticament (i a la nostra societat no s'ha fet res d'això), acabem reproduint-lo i seguirà estructurant el nostre present i el futur immediat (que és exactament el que està passant).

Del que es tracta, doncs, no és de "mantenir" una igualtat de fet que alguns qüestionen, sinó de ser capaços d'identificar les situacions de desigualtat per denunciar-les, corregir-les i impulsar noves polítiques i noves formes d'acció social que ens ajudin a superar les dinàmiques de desigualtat que hi ha establertes. Altra vegada, el mirall de la lluita feminista permet veure la gran diferència que hi ha entre les accions empreses per a superar les desigualtats de gènere i la inacció per a fer front al racisme: Quines lleis específiques s'han elaborat per a fer front al racisme? Quins mecanismes específics de denúncia i de suport a les víctimes s'estan fent servir? És equivalent la implicació i mobilització ciutadana, d'entitats, empreses $\mathrm{i}$ institucions per a fer front a un o altre problema? I la formació i sensibilització antiracista que reben els professionals és equiparable al que s'està fent en matèria de gènere? $\mathrm{El}$ consens social aconseguit en relació a les temàtiques de gènere i el patriarcat (repetim-ho: en gran mesura aparent i sempre preparat per a superar tergiversacions i resistències; però en tot cas, installat en una legitimitat i una capacitat de mobilització 
molt gran si del que es tracta és de defensar-1o) està molt lluny de l'acció antiracista, que aparentment es deixa en mans de l'activisme, que només en casos comptats rep el suport institucional i que encara en menys casos neix de la iniciativa de les institucions.

La mateixa manca de consens a l'hora d'identificar què és i què no és racisme ja és un bon indicador del camí que hi ha per córrer. Entre altres coses, perquè aquesta manca de consens tendeix a invisibilitzar i a legitimar algunes de les formes més flagrants de racisme, i impedeix que els professionals de l'acció social prenguin consciència de les dinàmiques de discriminació racista que condicionen el seu propi exercici professional.

Ens estem referint a les diferents formes de "racisme institucional", un concepte encara estrany al nostre país, però ben identificat en països amb una trajectòria de lluita antiracista molt més sostinguda en el temps i avalada per informes oficials i sentències judicials que al nostre país ens són totalment desconeguts i desconegudes (Cashmore, 1996; Gillborn, 2007; Macpherson, 1999; Schneider-Ross, 2003). Un treball seriós sobre el racisme institucional no només obriria la porta a la identificació i denúncia d'un marc legal i normatiu clarament racista (la Llei d'Estrangeria és difícilment compatible amb el respecte als Drets Humans per damunt de qualsevol diferència d'origen, i això ho afirma el reconegut catedràtic en filosofia del dret i filosofia política de la Universitat de València i especialista en polítiques migratòries, Javier de Lucas (2006a,b)), sinó que a més a més faria possible una reflexió sobre el racisme que posaria l'accent en les desigualtats que generen determinats mecanismes institucionals, enlloc de fer-ho només en les intencions (en l'existència o no d'una animadversió, d'una voluntat de discriminar) de les persones encarregades de fer funcionar aquests mecanismes (tot i que s'ha de dir i repetir: agradi o no, totes les actuacions institucionals tenen persones responsables, professionals que les tramiten i professionals que les executen). Aquesta manera d'entendre el racisme institucional permetria als professionals d'anar més enllà de la identificació de les "persones racistes" (que n'hi ha, però pensar que el racisme existeix en la nostra societat perquè "encara" hi ha una minoria fanàtica i ignorant, és un luxe que no ens podem permetre: equival a considerar que el racisme és una excepció, una rèmora del passat pròpia de persones i grups que podem identificar i aillar, i això està molt lluny de l'experiència de discriminació de les persones racialitzades), i ens permetria centrar-nos en les formes de desigualtat que es segueixen reproduint quotidianament, de vegades, fins i tot sense que els qui les reprodueixen en siguin conscients: els biaixos policials en la identificació de possibles 
delinqüents, les trajectòries acadèmiques desiguals que el sistema escolar reprodueix de manera sistemàtica, una doble xarxa escolar estretament associada a desigualtats econòmiques i d'origen de les famílies de l'alumnat, un apartheid residencial i discriminació d'accés a l'habitatge (la mà invisible d'Adam Smith segueix essent invisible, però mai ha estat cega), la invisibilització dels estils de vida, produccions artístiques, sistemes de creences i pràctiques socials dels grups minoritzats de la nostra societat (no només a l'escola: ¿què és el que fa que d'unes expressions culturals se'n faci càrrec la conselleria, el departament o la regidoria de cultura, i altres siguin assumides des dels serveis socials, per exemple?) (SOS Racisme Catalunya, 2020).

Si els professionals de l'acció social han d'assumir l'antiracisme com un eix central de la seva missió professional (perquè entenem que és així com hauria de ser), la formació d'aquests professionals ha de passar necessàriament per:

\section{Impulsar la seva capacitat d'identificar les diferents formes de racisme (el soci-} al, el polític il'institucional). I entenem que això implica superar definitivament el discurs de la interculturalitat, que no identifica correctament quin ha de ser l'objectiu prioritari de les polítiques i les accions en el camp de les migracions i la integració de les persones immigrades: si en aquest àmbit es produeixen vulneracions de drets, els poders públics i els professionals del camp social han de donar prioritat absoluta a la prevenció, la correcció i l'eliminació d'aquestes vulneracions; la resta de consideracions (entorn a la cohesió i la interacció social, els respecte a la diferència i els discursos sobre la igualtat) poden ser vàlides en la mesura que contribueixin a l'assoliment de l'objectiu principal o seran realitzables només si l'objectiu principal ja ha estat prèviament assolit.

\section{Entendre de quina manera interactua amb els altres eixos de desigualtat i quins} factors faciliten el seu desenvolupament. S'ha parlat molt d'interseccionalitat i sabem que les fractures socials s'accentuen quan els límits de les desigualtats socioeconòmiques coincideixen amb els línies amb què definim els diferents collectius en base als quals pensem la nostra societat, siguin aquests identitaris (europeus i africans, paios i gitanos, "moros", "negres" o llatinoamericans, si se'ns permeten expressions que no per ser políticament incorrectes, deixen de ser tan il·lustratives, com habituals), o siguin polítics i administratius (nacionals i estran- 
gers, perquè per molt que alguns insisteixin en això, els límits i les divisions no les provoquen només les identitats, sinó també unes estructures polítiques i legals que defineixen els nostres veïns de manera radicalment diferent i els atribueixen drets de manera clarament desigual). També les diferències de gènere (pensem en els permisos de treball, els processos de reagrupament familiar i el mercat laboral regular i irregular, repartit de manera desigual en funció de criteris de gènere), així com les diferències d'edat i les fenotípiques i de nacionalitat, esdevenen eixos de desigualtat que s'articulen de manera diferent amb les discriminacions de caràcter racista, generant realitats que romandran ocultes i sobre les quals no hi incidiran els discursos genèrics sobre la igualtat de drets i les polítiques pensades per a combatre un racisme que es suposa uniforme i que no ho és en absolut. Per reconèixer, incidir i transformar les múltiples situacions que es generen entorn a això que anomenem racisme, cal una formació específica que avui en dia no existeix. Sovint neguem realitats perquè les desconeixem, $\mathrm{i}$ alhora ens neguem a reconèixer les realitats que més qüestionen la forma idealitzada com tendim a pensar la nostra societat.

\section{Dominar recursos i estratègies per a fer-hi front i transformar les situacions} de desigualtat en situacions igualitàries, de solidaritat i cohesió social. Si el nostre coneixement de la realitat social sovint és superficial (de vegades, senzillament filtrat per l'accés que ens dona la interacció amb aquells que anomenem usuaris, persones que no constitueixen una mostra representativa d'uns sectors de població extremadament diversos, ni hem de suposar que es sinceren davant del que al cap i a la fi som: funcionaris -així podem ser vistos- que els donem o els retirem l'accés a recursos diversos), encara és més precari el coneixement dels recursos que tenim a l'abast per a lluitar contra un fenomen -el racisme-contra el qual, escassament s'hi ha lluitat els darrers anys, les darreres dècades... Dit d'altra manera: no deixa de ser curiós l'èxit d'idees tan simples com la de les "estratègies antirumors"! A què el podem atribuir? Podem pensar que el seu èxit rau en part al fet que, tot i que sabem que la clau de volta del racisme no radica en els rumors, almenys per a fer front als rumors hem estat capaços de generar unes accions que, com a mínim, semblen estratègiques! ¿Hi ha vida -hi ha estratègia?- més enllà de les estratègies antirumors? Si la lluita contra el racisme és central, ¿on és la caixa d'eines que posem a l'abast dels professionals per a lluitar-hi? 
I finalment, tot i que entenem que són dues qüestions molt importants, pensem que és necessari:

\section{Que els professionals de l'àmbit social assumeixin la lluita antiracista com un} compromís inherent i central del seu exercici professional (i podríem dir que de qualsevol exercici professional, atès que l'antiracisme hauria de ser una obligació ciutadana). En tot cas, ho ha de ser d'aquells que treballen en l'àmbit de l'acció social. Garantir la igualtat de drets entre totes les persones, i que aquesta no sigui només una declaració buida de contingut (una igualtat teòrica, en potència, que convisqui amb un marc legal, unes polítiques públiques i unes interaccions socials que la neguin de manera quotidiana) hauria de ser un dels principis sobre els quals haurien de descansar les polítiques públiques i les accions que desenvolupen els professionals de l’àmbit social. Si no "el" principi. Malauradament això no és així. Tots sabem que una de les tensions que provoquen els debats entorn al racisme en societats com la nostra, és que ens exposen a la contradicció radical entre allò que ens proclamem (que som una societat democràtica, que ens comprometem en la defensa dels Drets Humans, que vivim en un estat de social i de dret, etcètera, etcètera) i la trista realitat que de tant en tant algú posa en evidència (que som uns privilegiats -evidentment, uns més que altres- encantats de viure i gaudir dels nostres privilegis, que els neguem a altres persones i col-lectius, i que construïm arguments poc molt o gens sofisticats per a defensar-los; que els Drets Humans estan molt bé, però que encara estan millor les nostres fronteres; i que l'estat social i de dret és en realitat una enorme estructura de poder que quan ens fa nosa la critiquem, però que quan va a favor nostre no ens fa sentir tan incòmodes). I si l'antiracisme ha de ser inherent en l'exercici dels professionals de l'àmbit social, una de les primeres feines a fer hauria de ser la d'aprendre a reconèixer (tornem al punt 1, i al 2, el de la interseccionalitat) de quina manera el racisme travessa el seu exercici professional.

\section{Donar prioritat a l'atenció a les víctimes i ser capaços d'apoderar els col·lectius} racialitzats i la resta d'agents socials per a fer front a les diferents formes de discriminació racista. Prioritat perquè no pot ser que les víctimes siguin qüestionades abans que ateses. Primer protecció, vies de denúncia, dispositius de suport i mecanismes de seguiment, després ja s'escatiran els fets i s'establiran raons i desraons, interpretacions i malinterpretacions, víctimes, culpables, entesos i malente- 
sos; i s'arribarà a acords, rescabalaments o al que calgui. Però les persones no poden tenir por a denunciar, ni podem suposar que la majoria de les denúncies són interessades o resultat d'una hipersensibilitat que els aboca a atribucions de discriminació on no n'hi ha (no us sona? també és un recurs habitual del masclisme l'afirmació que les dones que són hipersensibles, que exageren i malinterpreten); ni es poden trivialitzar el que són vulneracions de drets fonamentals. Ara bé, com que aquestes coses (la trivialització, el menysteniment) passen i les inseguretats i les pors hi són, l'apoderament és indefugible. Els joves racialitzats, de fet, s'estan apoderant. La qüestió és si ho fan amb l'escalf i el suport del conjunt de la societat (de tots aquells que sentim simpatia pels "black lives matters" llunyans), o ho han de fer contra la societat, contra els professionals i contra les institucions. Pensem com s'està fent ara per ara, i pensem en quin dels dos bàndols -si és que podem reduir a dos bàndols enfrontats el complex taulell de joc que és la nostra societatcap a quin costat ens estem posicionant ${ }^{2}$.

Aquest darrer punt ens sembla fonamental: protecció, apoderament i solidaritat. Aquestes tres accions han estat fonamentals en moltes lluites. I per aconseguir la solidaritat moltes vegades ha estat clau la construcció d'una forta identitat per cohesionar els col·lectius ${ }^{3}$; en segon lloc, treballar per a la solidaritat interna i, finalment, per a l'extensió (l'obtenció) d'aquesta solidaritat més enllà dels membres de propi colllectiu. Però aquesta solidaritat i aquesta protecció a dia d'avui no es donen davant de situacions de discriminació racista. El nostre país és capaç de mobilitzar-se contra les expressions de racisme més flagrant que es desenvolupa als Estats Units, però quan aquest racisme desperta una onada de solidaritat entre les persones afrodescendents que viuen a Catalunya, aquesta reacció és viscuda amb estranyesa per part de la majoria de la població. Precisament quan la seva reacció ens hauria de fer reflexionar sobre les seves experiències a casa nostra, $\mathrm{i}$ ens hauríem de plantejar que moltes d'aquestes persones a més a més del color de la pell, comparteixen moltes altres coses i molt més profundes. Ex-

2.I informes com el de Kazyrytski (2013), que compara la realitat i les percepcions de joves de Salt amb les de molts dels joves francesos d'origen immigrat que han participat en revoltes urbanes els darrers anys, ens poden donar algunes pistes sobre quina pot ser la resposta a aquesta qüestió.

3. No per recrear-se en les identitats, sinó de utilitzar-les i posar-les al servei d'un projecte de transformació social i vinculat a la defensa d'uns drets que es reclamen com a universals (les "identitats-projecte" que Castells explica tan bé (1997: 28-34). Una qüestió, aquesta, de la qual en parlem en l'article que es publica en aquest mateix número de la Revista de Pedagogia i Treball Social, dedicat al "reconeixement". 
periències que diuen molt de nosaltres i de la manera com ens hi relacionem. Malauradament, però, hem tendit a trivialitzar l'experiència del racisme i com que l'hem entès com una expressió de fanatisme d'uns pocs, hem parat més atenció en aquests pocs suposadament fanàtics, més que no en els que de manera quotidiana es consideren victimitzats. Cal bastir aquests mecanismes de suport i protecció. No pot ser que determinades persones no denunciïn vulneracions de drets fonamentals per por que a partir de la seva denúncia se'ls pugui penalitzar (per trobar-se en una situació administrativa irregular, per exemple). No pot ser que les discriminacions racistes a l'hora d'accedir a un habitatge, en locals d'oci nocturn (d'aquestes n'hi ha cada dia de cada dia i els caps de setmana encara més), en gimnasos (recordem el cas del Punt Groc de Girona) o en bars (també habituals), siguin tractades com a problemes d'atenció al consumidor, quan es tracta d'una vulneració de drets fonamentals que trinxa el principi d'igualtat entre totes les persones. Per això dèiem que cal donar prioritat a l'atenció a les víctimes i en això els professionals de l'acció social tenen molt de camí per córrer. De fet, encara el tenen pràcticament tot, per córrer. I per això també dèiem que cal apoderar les persones i colllectius que es consideren víctimes de la discriminació racista, perquè lluny de qüestionar i minimitzar les seves denúncies, hem d'aprendre a escoltar-les i a prendre'ns-les seriosament. Són molts els col-lectius històricament discriminats, que per a fer-se valdre han hagut de fer front al ridícul, el menysteniment dels seus arguments, l'atribució d'actituds de queixa injustificada, la desqualificació del seu punt de vista. Per això, per a l'impuls de la lluita antiracista, hem d'aprendre quines han estat i són encara avui les formes de lluita que més i millor els han ajudat a transformar la realitat de molts collectius històricament discriminats. Per això mateix, els professionals de l'acció social haurien de conèixer quines lluites han hagut de lliurar molts d'aquests col·lectius, si el que volen és acompanyar els processos de transformació social.

\section{Bibliografia}

Bonnett, A. (2000) Anti-Racism. Londres: Routledge.

Cashmore, E. (1996) “Institutional Racism”, Cashmore, E. (ed.) (1996) Dictionary of Race and Ethnic Relations, Londres, Routledge.

Commissió per a la Igualtat Racial (CRE) (2007) CRE Briefings on a 'Framerwork for Fairness: Proposals for a Single Equality Bill for Great Britain', Londres: CRE. 
Generalitat de Catalunya (2017). Pla de ciutadania i de les migracions (2017-2020). Barcelona: Secretaria d'Igualtat, Migracions i Ciutadania.

Gillborn, D. (2007) “Segregació escolar i igualtat d'oportunitats. L'exemple del Regne Unit", Simposi sobre Immigració i educació a Catalunya, Barcelona, 17 y 18 de octubre. [Article en línia][Data de consulta: 27 de juliol de 2019].

Kazyrytski, L. (2013). "Revueltas urbanas de jóvenes inmigrantes: Francia y España. Un análisis comparativo". Indret: Revista para el análisi del derecho, 2, 1-32.

de Lucas, J. (2006a). "La ciudadanía basada en la residencia y el ejercicio de los derechos políticos de los inmigrantes". Cuadernos electrónicos de filosofía el derecho núm. 13 , 1-51.

de Lucas, J. (2006b). "La ciudadanía para los inmigrantes: una condición de la Europa democrática y multicultural”. Eikasia, núm. 4 , 1-19

Macpherson, W. (1999) The Stephen Lawrence Inquiry. CM 4262-I. Londres: The Stationery Office.

Parsons, C., Godfrey, R., Annan, G., Cornwall, J., Dussart, M., Hepburn, S., Howlett, K. \& Wennerstrom, V. (2004) Minority Ethnic Exclusions and the Race Relations (Amendment) Act 2000. Informe d'Investigació 616. Londres, Departament per a l'Educació i les Capacitats.

Pujal i Llombart, Margot (2005). El feminisme. Barcelona: UOC.

Schneider-Ross (2003) Towards Racial Equality: An Evaluation of the Public Duty to Promote Race Equality and Good Race Relations in England E Wales. Londres: Commissió per a la Igualtat Racial.

Serra, C. (2002). “El racismo observado. Etnografía y análisis de las relaciones interétnicas en el ámbito de la educación”. Cuadernos de Pedagogía, 315: 77-82. 
Serra, C. Besalú, X. i Casademont, X. (2016). "Lespai antiracista del gironès: una iniciativa comunitària, colllaborativa i interdisciplinària per donar resposta al racisme”. Pedagogia i treball Social. Revista de Ciències Socials Aplicades, 4 (2), 61-90.

SOS Racisme Catalunya (2020). InVisibles. L'estat del racisme a Catalunya, Informe 2019. Barcelona: SOS Racisme i Pollen Edicions. 
Xedagogia i Treball Social

Revista de Ciències Socials Aplicades

Edita: Universitat de Girona

Disseny i maquetació: info@clam.cat · 647427732

Dipòsit Legal: GI.904-2010

ISSN: 2013-9063 